\title{
The Relationship between Critical Thinking and EFL Learners' Speaking Ability
}

\author{
Raana Ramezani ${ }^{1}$, Ebrahim Ezzati Larsari ${ }^{1} \&$ Mohammad Aghajanzadeh Kiasi ${ }^{1}$ \\ ${ }^{1}$ Department of Linguistics and Foreign Languages, Payame Noor University, Tehran, Iran \\ Correspondence: Raana Ramezani, Department of Linguistics and Foreign Languages, Payame Noor University, \\ Tehran, Iran. E-mail: ranaramezany@gmail.com
}

\author{
Received: December 15, 2015 Accepted: May 10, 2016 Online Published: May 15, 2016 \\ doi: 10.5539/elt.v9n6p189 URL: http://dx.doi.org/10.5539/elt.v9n6p189
}

\begin{abstract}
The current study sought to investigate the relationship between critical thinking and speaking ability among EFL students at Payame Noor University (PNU) of Rasht. This research concerned determining the fact that whether language students who are as critical thinker, perform better in their speaking ability or not. In order to answer the research question and test the hypothesis, 100 PNU English students were selected by applying IELTS speaking test as the samples of this study. Then in order to figure out critical and uncritical learners, Lauren Starkey Critical Thinking Test including 30-multiple choice item was administered to the participants. After that, based on the obtained data and due to lack of normal distribution, Spearman non-parametric correlation was employed. The findings of the current study revealed a significant correlation coefficient among these two major variables. In fact, those English learners who were recognized as critical thinkers performed better in their speaking.
\end{abstract}

Keywords: critical thinking, speaking skill, distance learning, EFL learners

\section{Introduction}

As Willingham (2007) asserted one of the basic yet inadequately met, goal of schooling is to enable students to think critically which consists of examining both sides of an issue, being open to new affirmations that may refute your ideas, believing that claims be inferred by evidence, observation, induction and deduction and so forth. In scholars' point of view, critical thinking can be defined as mental and cognitive activities which is a subset of three sorts of thinking: reasoning, decision making and judgement and problem solving.

Warnick and Inch (1994) define critical thinking as "involving the ability to explore a problem, question or situation; integrate all the available information about it; arrive a solution or hypothesis; and justify one's position." (p. 11).

Based on Arum and Roska (2011), "99 percent of college faculty say that developing students' ability to think critically is a very important or essential goal of undergraduate education". (p. 11).

According to Facione (2007), There are mental and cognitive abilities and skills which can be put at the core of critical thinking including: interpretation, analysis, evaluation, inference, explanation, and self-regulation.

Interpretation deals with perceiving and stating the meaning or implication of a specific situation, experience, evidence, opinions, data, rules and regulations, process and procedures and criteria. Decoding significance, categorization and express and clarifying meanings are the subskills of interpretation (Facione, 2007).

Analysis can be defined as figuring out the actual and intentional association among concepts, ideas, beliefs, questions, events or experiences. Identyfing ideas, distinguishing arguments and analyzing them are the subskills of analysis (Facione, 2007).

Evaluation is to investigate the reliability and credibility of statements or evidence based on person's opinion, situation, judgment and determine the logical and rational relationships between different statements in various circumstances (Facione, 2007).

Inference means to distinguish and specify the elements and features to come up to the conclusions, make hypotheses, figure out relevant information and reach the outcome of data, experiences, statements and situations. Querying evidence, speculating choices and come to the conclusions are the subskills of inference (Facione, 
2007).

Facione (2007) holds the opinion that Explanation can be defined as expressing the results of one's reasoning in a logical and meaningful way and being able to present an overview and a full look at the whole events and evidence. The subskills under explanation are expressing the methods and outcomes, explaining procedures, defending and supporting the logic and rational behind the issues.

Facione (2007) also states that Self-regulation means controlling and monitoring one's mental activities and cognitive abilities and the features applied in those activities by using different skills in analysis and evaluation the performances, making judgments toward questioning, certifying and confirming the results or reasoning.

Scholars believe that speaking skill is the most important part of an EFL course. With the improvement of technology and the need for interaction in community, many students attend language classes to promote their ability to speak. Students with the higher and better experiences in society to communicate with others are more successful in speaking skill (Malmir \& Shoorchech, 2012).

Accuracy and fluency are two important factors which can determine the success of English learners in the future. Accruacy is the ability to produce correct sentences using correct grammar and vocabulary. Accuracy is relative. A child in early primary isn't capable of the same level of accuracy as an adult. Teachers who concentrate on accuracy help their students to produce grammatically correct written and spoken English.Fluency is the ability to speak easily, smoothly and expressively. In other words, the speaker can respond in a language clearly, concisely and effortlessly, while relating meaning and context (Malmir \& Shoorchech, 2012).

According to Folse (2006), for most people the ability to speak a language is synonymous with knowing that language since speech is the most basic means of human communication.

\subsection{Statement of the Problem}

Whenever people find out what to do in a logical and reflective manner, in order to figure out reasonable solution toward complex problem, analyzing the methods and presupposition in arriving at scientific hypothesis, they think critically. By applying and conducting the critical thinking skills, speaking ability among students can substantially improve. Speakers take a more dynamic role in speaking and try to understand and make decision in challenging circumstances (Malmir \& Shoorchech, 2012). This can be very important between Payame Noor University (PNU) students due to lack of time and limited number of sessions which are the characteristics of distance learning, that is to say because of some demerits of distance learning, like narrow choice of materials, no frequent review and delayed feedback, improving the oral skills in this system will be highly effective.

Having been studied at PNU educational system, the researcher experienced the problems which students deal with in this system. Students do not have enough time to ask any question or share their ideas in classroom, so the syllabus have to prepare and cover in a limited time by teacher without giving any opportunity to speak freely and it reveals some of the shortcomings of this system. In fact, in such a context, the one is successful who can understand the materials well, infer the meaning from surface in various conversations, reason logically and ask relevant questions in a limited time of a class. So we can say improving oral skills is essential in this system. Therefore, involvement in discussion, better and faster judgment and distinguishing between different situations which are the characteristics of an active or critical thinker, may lead PNU students to engage in class debates, willing to ask questions (as an oral skill) and speak more in the classroom.

Critical thinkers' feedback can be very fruitful to the other learners in order to understand better and to make reasonable connection between different ideas, arrive at conclusions and finally successful international communication (Malmir \& Shoorchech, 2012).

Although, various studies by different researchers such as Malmir and Shoorcheh (2012), Sanavi and Tarighat (2014), conducted in this area, and they recognized the impact or any possible relationships between critical thinking and the other concepts and skills in TEFL, there are still lots of problems regarding the ability to speak well as one of the fundametal aspect of an English student. There are many graduated English students who are not able to speak fluently and accurately. So, the current study aimed at promoting speaking skill at PNU context with the distance learning educational system and its relationship to the critical thinking concept.

\subsection{Research Question and Hypothesis}

Q. Is there any relationship between critical thinking and speaking ability of PNU students who major in English?

H. There is no relationship between critical thinking and speaking ability of PNU students who major in English. 


\subsection{Purpose of the Study}

The goal of this study was to provide an insight into critical thinking and speaking ability of Rasht PNU EFL students. Being critical thinker at PNU is very imperative, because it may lead students to involve in discussion, ask more questions, better and faster decisions and finally take more benefits in a short time and limited number of sessions which are the characteristics of distance learning. Moreover, the critical thinkers' feedback may have positive impact on the other students in order to take a more dynamic role in their speaking. Therefore, this study concerns determining the relationship between being critical thinker and able to speak well.

\section{Review of Literature}

\subsection{A brief history of the Idea of Critical Thinking}

The intellectual roots of critical thinking according to Paul, Elder, and Bartell (1997) date back to Socrates teaching methods and perceptions about 2500 years ago, who detected by a teaching practice and questioning that people could not logically support their claims to different ideas. He highlighted the essential of asking deep questions that make people into thinking before accepting any opinion. The significance of questioning, pursuing evidence executing arguments closely examining main assumptions and concepts, and discovering the inferences of what ia said and what is done, was established by Socrates. His teaching practice and probing questioning method is now known as "Socratic Questioning" and is the best known strategy and technique for critical thinking.

Plato, Aristotle and the Greek scholars followed Socrates' method and believed that things are often different form what they appeared and only trained mind is able to figure out the reality of things. Based on these traditions, for those who was eager to recognize the deeper realities, the need to think rationally, logically, systematically was felt in order to detect implications from the delusive appearances deeply and exactly, for the only thinking which can take us beyond the surface, is thinking critically that is inclusive, well-reasoned, comprehensive, and responsive to objections (Paul, Elder, \& Bartell, 1997).

The idea of systematic critical thinking was represented in the writings by Thomas Aquinas in the Middle Ages. The potential ability of reasoning and also the need for systematic reasoning was empowered by him. Based on Aquinas' thinking, critical thinkers do not always discard the established rules or ideas, only those that lock logical basis. Thinking critically about different problems, situations and issues such as religion, art, humanity, society and the need to think systematically was started since the time of Renaissance (15th and 16th centuries). In England, Francis Bacon in his book The Advancement of Learning, argued explicitly the crucial of systematic thinking and studying the universe empirically. He called bad habits of thought (idols) that lead people to believe what is false or misleading. Descartes wrote the second text in critical thinking, called Rules for the Direction of the Mind, some fifty years later in France. He argued and defended the need for clarity and precision in thinking, and developed a method of thinking based on the principle of systematic doubt, means that every aspect of thinking and ideas should be questioned, doubted and tested. "I think, therefore I am" is the famous words of Descartes who emphasized the importance of utilizing skillful way of thinking (Paul, Elder, \& Bartell, 1997).

The critical thinking movements has widespread impact on the day-to-day life of human beings. The overview of critical thinking approaches revealed that the ideas and beliefs without considering the logical and rationale behind them, may be a sort of prejudgment and prejudices and restrict the perspective and learners' point of views. So having the critical eyes into different evidence is a crucial prerequisite of rational action and knowledge (Paul, 1985).

One of the primary objectives of schooling and education is the ability to think critically, so nowadays, providing the students with critical thinking skills by different procedures and approaches is crucial in various educational fields worldwide (Paul, 1985).

Having sufficient content knowledge is one of the imperative preconditions of the ability to think critically. Learners will not be able to have a critical view to the evidence, if they have little knowledge or information about the topic, in that case, executing the topic in order to figure out the best solution (Willingham, 2007).

Some studies like the above mentioned were conducted in the area of critical thinking and sought to determine the connection of different skills with this concept. Among the researches which were performed on this concept, the studies by Malmir and Shoorcheh (2012) and Sanavi and Tarighat (2014), have more relationships with the current study. Although, the present study is different in some aspects. This is a correlational study at Rasht PNU with the distance learning system of education and specific features and shortcomings such as limited number of sessions, lack of time, and delayed feedback in order to figure out the relationship between critical thinking and speaking ability and finding out how the possible interrelation among these two concepts can influence and 
promote teaching and learning processes.

\subsection{Speaking Skills}

It seems that speaking is the most crucial among the other language skills, since 'Speaker' of a language referred those who know a language well, as if all other skills of language (listening, reading and writing) included in speaking skill (Ur, 1996).

While speaking, the one can reveal that how much he/she knows a language, how much demonstrate the correct grammar, vocabularies and so forth. Therefore, speaking can cover other language skills and is essential to improve it in a great manner.

Speaking skills can be defined as the most important part of an EFL course. With the improvement of technology and the need for internationl communication in the current century, language learners take part in language classes to enhance their ability of speaking. Those learners who are more effective in their speaking performances are much more successful and effective in school and in other areas of their lives (Malmir \& Shoorcheh, 2012).

Based on Folse (2006), most people believe that knowing a language means the ability to speak a language since speech is essential in order to communicate in the society with the other people, but speaking a language for foreign language learners can be very difficult because adequate oral interaction requires the ability to utilize the language appropriately in social communication. Interaction involves not only verbal communication, but also paralinguistic elements of speech such as stress, pitch and intonation (Seligson, 1997; Fulcher, 2003).

Oral and spoken interaction concerns producing and negotiating language in a different way which is used in writing. Speakers and listeners deal with producing and processing language in spoken interaction at the same time, but these two skills are highly sensetive and greatly dependent on time constraints which means that they must process language as they go without any opportunity to go back, check and make necessary changes. Speakers must also consider the relationship with others or to whom they are listened and based on the meaning they wish to convey adjust their language (Thornbury, 2007).

Among the macro skills of language, speaking is the most difficult skill to assess meaning that recognizing oral ability is difficult (Joiner \& Jones, 2003). Speaking is an interactive process of constructing meaning that involves producing, receiving and processing information (Brown, 1994; Burns \& Joyce, 1997).

Speaking is highly dependent on the context in which it occurs. The participants, their background knowledge, the aim, the subject experiences and physical and mental circumstances may have effect on form and meaning of speaking.

A speaker's skill and speech habits have an impact on the success of any exchange (Van Duzer, 1997).

Speakers must be able to anticipate and then produce the expected patterns of specific discourse situation. They also manage discrete elements such as turn taking, rephrasing, providing feedback or redirecting (Burns \& Joyce, 1997).

According to Luoma (2004) two methods are applied for determining and assessing speaking skill. Observational approach in which the students' behavior and performance is observed and assessed immodestly. In the structured approach, the students are required to perform one or more specific oral communication tasks. Then their performances on the tasks observed and evaluated. The task can be applied indirectly or in a group. In the present study we administered structured approach for interviewing each learner individually (as cited in Malmir \& Shoorcheh 2012).

\subsubsection{Features of Spoken language}

In order to discuss the nature of spoken language, we must be clear about different aspects of spoken language. For example Carter (2004) states creativity as a 'feature of spoken language'. For Miller and Weinert (1998) the simplicity of noun phrases is an important characteristics of spoken language.

Here we deal with four features of spoken language: Prosody, Fluency and Accuracy, Grammatical and Lexical Features and Corrective Feedback and Evaluation.

\subsubsection{Prosody}

According to Chafe (1994) prosody refers to pauses, prominences, pitches and changes in the quality of voice which strengthen spoken interaction. Chafe (2006) states that "spoken language is produced in prosodic phrases or in other words, intonation units, regardless of whether read aloud or spontaneously spoken" (p. 62).

Chafe (1994) describes these intonation units as "changes in pitch or voice quality as changes in the duration of 
syllables and words, as well as alternating with speaking and a dialogue (p. 63).

Hughes and Szcepek (2006) note that "turn- taking in a dialogue is heavily influenced by prosody, as interlocutors rely on prosodic cues in addition to syntactic cues when taking their turn as a speaker" (p. 127).

Based on the definition it can be said that prosody is likely to affect fluency. Wennerstam (2000) considers the role of prosody in fluency and stares that "fluent speakers do use pitch levels to indicate relationships between phrases and to segment their speech into turns" (p. 116).

\subsubsection{Fluency and Accuracy}

While talking about teaching speaking skills, the first concept which normally come to mind is fluency/accuracy dichotomy (Solcova, 2011).

Based on Segalowitz (2003) fluency is "an ability in the second language to produce or comprehend utterences smoothly, rapidly and accurately" (p. 384). It reveals that both concepts are closely related to each other. Two important aspect can influence fluency: Speed of delivery and regularity means a natural amount and distribution of pauses (Bygate, 2009).

Koponen and Riggenbach (2000) state that "it is impossible to define fluency as a unitary concept" (p. 5). Carrol (2004) notes that "in discussions on second language talk, it is not well established what exactly causes the perceived non-fluency" (p. 202).

Koponen and Riggenbach (2000) continue to discuss that "within language assessment discussions fluency is therefore often understand as a lack of excessive breaks in speech" (p. 8).

Freed (2000) also notes that "the terms competence, proficiency and fluency are indeed commonly used interchangeably, and also given multiple definition" (p. 244).

Lennon (2000) defines fluency as "the rapid, smooth, accurate, lucid and efficient translation of thought or communicative intention into language under the temporal constraints of on-line processing" (p. 26).

In sum, there does not a single definition for fluency, for example Lennon (2000), Wennerstam (2000), Freed (2000) and Carroll (2004) state that pauses, breaks, hesitations, repeats and other such phenomena do not reveal that the speaker is not fluent.

\subsubsection{Grammatical and Lexical Features}

Miller and weinert (1998) discuss spoken language grammar and state that the phrases and cluses in spoken language are syntactically simpler than in written language. In addition, Mc Carthy (1998) holds the opinion that spoken language deal with certain types of ellipsis, such as auxiliary verbs, subject pronouns and articles.

As regard the lexical aspects of spoken language, Riggenbach (1998) notes that "the range of spoken language vocabulary differs from that of written language" (p. 63).

Regarding casual conversation, Mc Carthy (1998) notes that, the vocabulary tend to be marked with relational function, in order to establish social relations between the interlocutors, rather transmiting information.

\subsubsection{Corrective Feedback and Evaluation}

According to Solcova (2011), error correction or correction feedback is closely related to the concept of accuracy and thus to teaching speaking. Those errors which do not change the meaning are usually overlooked in real life. Similarly, those errors of second-language speakers which do not interfere with meaning are normally ignore (Light bown and Spada, 2006). Therefore, it sounds unnatural if teachers focus on correcting the structures and grammar rather than meaning. Although error correction can be helpful, over-correction of errors may have negative impact for further speaking production especially when the learners' thoughts in interrupted by the teacher error correction, while the learners try to express their ideas and thought (Solcova, 2011).

\section{Methodology}

Speaking skill as one of the fundamental abilities of English students is highly important and imperative especially in TEFL. The researcher encountered many graduated English students who are not able to talk accurately and fluently. This problem even is more severe at PNU context due to its special educational system (distance learning) with the deficiencies such as lack of enough time, limited number of sessions, delayed feedback which can intensify the problem. The present study amied at investigating the interrelationship between critical thinking and speaking performance among English students at Rasht PNU to figure out its influences on promoting speaking skill. 


\subsection{Design of the Study}

This quantitative research concerns determining the correlation between two different variables. Quantitative research is a data-led method which provides data that can be accurately and precisely measured. The specific research design was correlational; this type of research is typically identified as lack of treatment or any comparison groups.

\subsection{Participants}

The population of the current study were about 325 EFL students learning English at Rasht Payame Noor University (PNU). The sample size based on Morgan (1970) table was 175 English students which were chosen by random sampling. Both male and female students participated in this study. The students were originally from Guilan state; with the same cultural and notional background and the span of students' age was between 22-30 years old.

\subsection{Instruments}

In order to investigate the correlation between two major variables, the following instruments were applied:

\subsubsection{IELTS Speaking Test}

As the first step, IELTS speaking test was administered to check the proficiency level and come up with the homogenized group.

\subsubsection{Lauren Starkey (2010) Critical Thinking Test}

This test including 30-multiple choice item was employed to the participants to figure out critical and uncritical thinkers.

\subsection{Data Collection Procedures}

In order to answer the research question and test the hypothesis of the study, the following steps were implemented: First, to ensure the homogeneity of the participants, IELTS speaking test was applied to the participants. In this case, oral interview was held and the voice of students was recorded. Then, these recordings were submitted to two experienced teachers of both genders in order to guaranty the reliability. The average scores given by these experts were the real scores of students' performances which was guaranteed inter-rater reliability. From the total population who took part in the testing session, those learners whose scores were one standard deviation above and below the mean were selected as the subjects of this study.

Afterwards, Lauren Starkey critical thinking questions including 30-multiple choice item were provided for the participants to figure out critical and uncritical thinkers. Finally, a correlational statistics was employed to determine the possible relationship between critical thinkers and speaking ability of EFL learnes.

\subsection{Data Analysis Procedure}

As it has already been mentioned, the researcher concerns determining the fact that whether language students who are as critical thinker, perform better in their speaking ability or not. Hence, to analyze the obtained data, the statistical procedures used for measuring the correlation between two variables was Spearman non parametric method, because we did not deal with normal distribution. The test generated a series of tables that has defined the relationship between two variables. The hypothesis of the study was tested through the statiscal methods. All of statistics were measuerd through SPSS software.

\section{Results}

In the present study, English students studying at Rasht PNU were considered. To make sure that all students are at the same proficiency level, IELTS speaking test was applied to the sample students. All subjects were asked the same questiones. The interviews were recorded for further detailed scoring. In order to ensure the inter-rater reliability of the assessments, each tape-interview was rated by two raters. The average score given by these two raters, were the students' real score. Those students whose scores were one standard deviation above and below the mean were selected as the subjects of this study.

Afterwards, Lauren Starkey critical thinking questions including 30-multiple choice item were used to distinguish critical and uncritical thinkers. Finally, in order to figure out the relationship between variables, a correlational statistics employed. According to the obtained data and non normal distribution, non parametric Spearman was applied in order to calculate the correlation between the above mentioned variables.

\subsection{Descriptive Statistics}

In order to answer the research question and test the hypothesis, the collecting data were analyzed in the 
following order: To examine correlation between two continuous variables, correlation coefficient was employed. For this purpose, at first step normality test was applied in order to recognize whether distribution is normal or not. Then according to the results of the normality test, the researcher assigned the type of method that could be employed: Pearson parametric method or Spearman non-parametric method.

In order to figure out the exact probability of normality, the results of Kolmogorov-Smirnov test has reported for critical thinking and speaking ability in the below table. Two statistical probability in the test are:

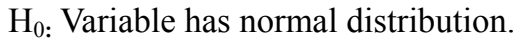

$\mathrm{H}_{1}$ : Variable has not normal distribution.

Table 1. Probability of normality

\begin{tabular}{lllll}
\hline Variable & Observation & Kolmogorov-Smirnov Test (KS) & Significant Level & Result \\
\hline Critical thinking & 100 & 1.593 & 0.013 & Non normal \\
Speaking ability & 100 & 1.069 & 0.203 & normal \\
\hline
\end{tabular}

Based on the results, probability of normality for critical thinking variable statistically, is not acceptable. $(\mathrm{KS}=1.593$, Sig. $<0.05)$. On the other hands probability of normality for speaking ability variable is acceptable $(\mathrm{KS}=1.069$, Sig. $>0.05)$. Considering the result (Non normality of one variable) for determining the correlation between two variables, Spearman non-parametric method was employed.

\subsection{Correlation Analysis}

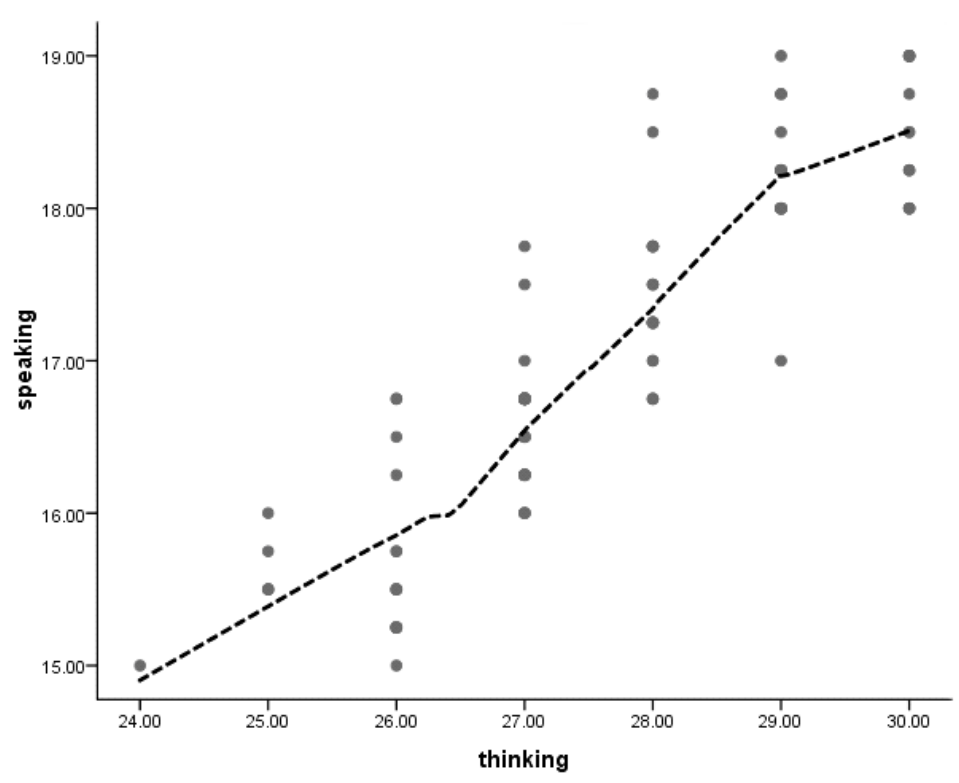

Figure 1. Scattering graph of speaking ability against critical thinking

In this section the researcher has investigated correlation between two variables: critical thinking and speaking ability. Before doing so, it's very effective to see the scatter graph of these two variables, because by applying this graph all possible patterns between two variables can be clarified very well. The following graph has shown scatterings of critical thinking and speaking ability. In addition, the scattering pattern of spots has specified by locally smoothing. According to the graph, it can be revealed that by increasing the critical thinking levels, the ability to speak has significantly improved. So it can be predicted that there has been significant correlation between critical thinking and speaking ability.

The following table has clarified the results of Spearman correlation coefficient between critical thinking and speaking ability. Statistical probability in this test can be stated as follow: 
$\mathrm{H}_{0:}$ There is no correlation between critical thinking and speaking ability.

$\mathrm{H}_{1}$ : There is correlation between critical thinking and speaking ability.

Table 2. Correlation between variables

\begin{tabular}{lll}
\hline & Index & Speaking Ability \\
\hline Critical thinking & Spearman Correlation Coefficient & 0.915 \\
& Significant Level & 0.000 \\
\hline
\end{tabular}

According to the results, there has been strong correlation coefficient $(\mathrm{r}=0.915)$ between these two variables which is statistically significant. Therefore based on the obtained date, the hypothesis of the present study (there is no relationship between critical thinking and speaking ability of PNU students who major in English) was rejected (r=0.915, Sig. $<0.05$ ).

\section{Conclusion}

English students at Rasht PNU were studied to investigate the possible relationship between critical thinking and their speaking ability among their population. The specific design of this quantitave study was correlational due to lack of applying any treatment. Then IELTS speaking test was employed and the voice of students were recorded in order to submit them to two experienced teacher of both genders. In order to achieve the inter rater reliability, the average scores given by these experts were the real scores of students' performances. Afterwards, Lauren Starkey critical thinking test inclouding 30-multiple choice item was provided to recognize critical and uncritical thinkers. Finally, as the researcher was engaged in non normal distribution, a non parametric Spearman correlational statistics was used to determine the relationship between the above mentioned variables.

Based on the results of the present study, the correlation coefficient index

$(r=0.915, \operatorname{sig}<0.05)$ is statistically significant, means that there has been a strong positive correlation between critical thinking and the ability to speak English. In fact, by increasing the critical thinking level, the ability to speak English is significantly improved. Therefore, English students who are as critical thinkers and be able to decision logically, as the results of the study indicated; also show better performances on their speaking ability. So, the research hypothesis was rejected.

The findings of the present study were in accordance with the results of previous studies regarding the impact or relationship between critical thinking and speaking performances. Mostly there has been an agreement between the findings revealed by Malmir and Shoorcheh (2012) which investigated the impact of critical thinking on Iranian EFL learners' speaking ability. The other research by Sanavi and Tarighat (2014), which was intended to investigate the impact of teaching critical thinking skills on the speaking proficiency of Iranian EFL learners in Tehran was in accordance with the current study. In both cases, the strong significant positive impact on the above mentioned variables were recognized. Although, as it has been already mentioned that there were strong relationships among the current study and the ones which were pointed out above, this study is different in some aspects. This research was a correlational study at Rasht PNU with distance learning educational system and some features and shortcomings such as limited number of sessions, lack of enough time and delayed feedback which may likely has an impact on the teaching and learning processes. In spite of the findings which can be inferred from different studies, there are some limitations that maybe the researcher is not able to control them. One of these factors can be the sample size and it was less than the required one based on Morgan (1970) table. The reason was related to the students' final examiations, bring the questionnaire after deadline, and etc. The other factors such as non normality distribution, gender, and their background and notional characteristics may likely affect the validity of the research.

\subsection{Implications and Recommendations}

The outstanding pedagogical implications in this research correspond with the statements of the following researchers: Worrell and Profetto-Mc Grath (2007) noted that employing critical thinking activities can increase learners' level of thinking and help language learners enhance their speaking abilities simultaneously. Critical thinking can enable the learners to go beyond the surface and information which can be provided by the other participants during the conversation.

The outcome of the present study revealed information which can be extremely effective especially in TEFL, indicating that a critical thinker is a better language student, because critical thinkers can ask appropriate 
questions, relevant information, reason logically based on the available data and come to reliable and truthworthy conclusions about the others' opinions in various setting.

The current study sought to emphasize that critical thinking and speaking are interdependent and interrelated. Vygotsky (1962) noted the interdependence of thought and speech and has highlighted that thinking motivates speaking and vice versa. Thinking is not confined to speaking ability, other language skills are all related to thinking. In fact, the hidden basis of all cognitive activities is thinking. The findings of this research can be helpful and effective for those students who study in the distance learning system, especially English students due to the crucial role of promoting oral and speaking skills.

The significant results of determining critical thinkers in TEFL are not limited to speaking ability and they are helpful for other language skills. By the time the students are critical thinkers, they would be more successful in their speaking performances. Students who are not critical thinkers, would perform poorly on their speaking ability. knowing these facts, both students and teachers will be aware of the crucial role that critical thinking has in the students' speaking ability. Therefore, the teachers' recognition of critical thinkers can change the teaching and learning process. The teacher also can assist the uncritical thinkers by introducing and teaching critical thinking strategies in the classroom.

The university which was considered in this study (Rasht PNU), may suggest to central organization that revise the contents of students' text books. It also can be proposed that considering the type of questions which can involve students' critical thinking may likely improve this concept among students due to its characteristics such as self study and distance learning. Descriptive question type would be more effective than multiple choice questions. The professors also must be familiar with this concept and perform critical thinking instructions in the classroom, in order to activate this quality especially for English learning students in which the ability to speak fluently and accurately is extremely important.

To recapitulate, the problems which the researcher deals with at PNU and it has already been mentioned, having a critical eye to different issues may improve the speaking performances of English learners. As the results of this research indicated there has been a strong correlation between critical thinking and speaking ability which led the hypothesis to be rejected. The previous investigations which were conducted by different scholars such as Malmir and Shoorcheh (2012) and Sanavi and Tarighat (2014) supported the idea that applying critical thinking in various English skills and abilities would be extremely effective. By eliminating the above mentioned shortcomings of PNU, it can be predicted that the psychological properties of learning would be standout.

\section{Acknowledgement}

I would like to express my gratitude to my dear God and then to my professors Dr. Ezzati and Dr. Aghajanzadeh, for their devoted instructions and profound comments. Most of all, I appreciate my parents for what they sacrificed through my life. We are often so busy growing up that we forget our parents are also growing old.

\section{References}

Arum, R., \& Roska, J. (2011). Academically Adrift; Limited Learning on College Campuses. Chicago: University of Chicago Press.

Bygate, M. (2009). Teaching the spoken foreign language. In K. Knapp, \& B. Seidlhofer (Eds.), In Handbook of Foreign Language Communication and Learning, 6, 401-438. Berlin: Mouton de Gruyter.

Carrol, D. (2004). Restarts in Novice Turn Beginings: Disfluencies or International Achievements? In R. Gardner, \& J. Wagner (Eds.), Second Language Conversations (pp. 201-220). Chippenham: Continuum.

Brown, H. D. (1994). Teaching by principles: an interactive approach to language pedagogy. Englewood Cliffs, NJ: Prentice Hall Regent.

Burns, A., \& Joyce, H. (1997). Focus on Speaking. Sydney: National Center For English Language Teaching and Research.

Chafe, W. (1994). Discourse, Consciousness, and Time. Chicago: The Chicago University Press.

Chafe, W. (2006). Reading Aloud. In R. Hughes (Ed.), Spoken English, TESOL, and Applied Linguistics: Challenges For Theory and Practice (pp. 53-71). NewYork: Palgrave.

Facione, P. A. (2000). The disposition to toward critical thinking: Its character, measurment, and relation to critical thinking skill. Informal Logic, 20(1), 61-84.

Facione, P. A. (2007). Critical Thinking: What it is and Why it counts.

Folse, K. (2006). The art of teaching speaking. Michigan: Michigan University Press. 
Freed, B. (2000). Is Fluency, Like Beauty, in the Eyes (and ears) of the Beholder? In H. Riggenbach (Ed.), Perspectives on Fluency (pp. 243-265). Ann Arbor: The University Press.

Fulcher, G. (2003). Testing second language speaking. NewYork: Pearson Longman

Hughes, R., \& Szcepek, R. B. (2006). Factors Affecting Turn-Taking Behaviour: Genre Meets Prosody. In R. Huges (Ed.), Spoken English, TESOL, and Applied Linguistics: Challenges For Theory and Practice (pp. 126-140). New York: Palgrare.

Joiner, R., \& Jones, S. (2003). The effect of communication medium on argumentation and the development of critical thinking. International Journal of Educational Research, 23(4), 1364-1375.

Krejcie, R. V., \& Morgan, D. (1970). Journal of Educational and Psychological Measurement. EDUC PSYCHOL MEAS, 30(3), 607-610.

Koponen, M., \& Riggenbach, H. (2000). Overview: Varying Perspectives on Fluency. In H. Riggenbach (Ed.). Perspectives on Fluency (pp. 5-24). Ann Arbor: The University Press.

Lennon, P. (2000). The Lexical Elenent in Spoken Second Language Fluency. In H. Riggenbach (Ed.), Perspectives on Fluency. Ann Arbor: The University of Michigan Press.

Lightbown, P. M., \& Spada, N. (2006). How Languages are Learned (3rd edition). Oxford University Press.

Luoma, S. (2004). Assessing speaking. NewYork, Cambridgr University Press.

Malmir, A., \& Shoorcheh, S. (2012). An investigation of the impact of teaching critical thinking on Iranian EFL learners' speaking skill. Journal of Language Teaching and Research, 3(40), 608-617.

Mc Carthy, M. (1998). Spoken Language and Applied Linguistics. Cambridge: Cambridge University Press.

Miller, J., \& Weinert, R. (1998). Spontaneous Spoken Language: Syntax and Discourse. Oxford: Claredon Press.

Paul, R. (1985). The Critical Thinking Movement in Historical Perspective.

Paul, R., Elder, L., \& Bartell, T. (1997). Taken from the California Teacher Preparation for Instruction in Critical Thinking: Research Findings and Policy Recommendations: State of California.

Sanavi, V. R., \& Tarighat, S. (2014). Critical thinking and speaking proficiency: A Mixed- Method Study. Theory and Practice in Language Studies, 4(1), 79-87.

Segalowitz, N. (2003). Automaticity and Second Languag. In C. Doughty, \& M. Long (Eds.), The Handbook of Second Language Acquisition (pp. 382-408). Oxford: Blackwell Publishers.

Seligson, P. (1997). Helping students to speak. Richmond Publishing.

Solcova, P. (2011). Teaching Speaking Skills.

Starkey, L. (2010). Critical Thinking Skills Success In 20 Minutes A Day. NewYork, Learning Express.

Thornbury, S. (2007). How to teach speaking. Pearson Longman.

Ur, P. (1996). A course in language teaching: Practice and theory. Combridge: Cambrige University Press.

Van Duzer, C. (1997). Improving ESL learnes' listening skills: At the workplace and beyond. Washingtone, DC: Project in Adult Immigrant Education and National Clearinghouse for ESL Literacy Education.

Vygotsky, L. (1962). Thought and Language. Cambridge, Massachusetts: The MIT Press.

Warnick, B., \& Inch, E. (1994). Critical Thinking and Communication (2nd ed.), NewYork: Macmillan.

Wennerstam, A. (2000). The Role of Intonation in Second Language Fluency. In H. Ann (Ed., pp. 102-127) Arbor: The University of Michign Press.

Willingham, D. T. (2007). Critical thinking: Why is it so hard to teach? American Educator, 8-19.

Worrell, J. A., \& Profetto-McGrath, J. (2007). Critical thinking as an outcome of context-based learning among post RN students: A literature review. Nurse Education Today, 27, 420-426.

\section{Copyrights}

Copyright for this article is retained by the author(s), with first publication rights granted to the journal.

This is an open-access article distributed under the terms and conditions of the Creative Commons Attribution license (http://creativecommons.org/licenses/by/3.0/). 